\title{
Influencias judías en la literatura castellana medieval
}

\author{
PALOMA DÍAZ-MAS \\ Facultad de Filología, Geografía e Historia \\ Universidad del País Vasco. Vitoria
}

La primera cuestión que se plantea ante un título como éste es qué entendemos exactamente por influencias judias en una literatura (en nuestro caso, la medieval escrita en castellano): ¿la presencia de temas judíos, la utilización de fuentes hebreas, la imagen del judío como persona y como colectividad, el trasfondo judaico de la cultura de los conversos, la visión que tuvieron del judaísmo los cristianos de la Castilla medieval, la participación de hebreos en obras culturales cristianas?

Semejante matización no es baladí, porque tratándose de temas judíos muchas veces se ha incurrido en imprecisiones terminológicas o en errores de concepto que han oscurecido o confundido nuestra visión de la presencia y la influencia de lo judío en la cultura hispánica.

\section{TIPOLOGÍA DE LAS INFLUENCIAS JUDÍAS}

En algún otro lugar ${ }^{1}$ he propuesto una tipología de las influencias judías en la literatura española que quizás convenga recordar y matizar aquí. Es obvio que no podemos dar el mismo tratamiento a las obras escritas por judíos, por cristianos o por conversos. De entre las segundas, conviene matizar entre las influencias que son consecuencia de la participación de judíos en empresas culturales cristianas (como la producción de libros científicos en las escuelas alfonsíes del siglo xIII o los romanceamientos bíblicos hechos con el concurso de judíos), las obras cristianas que utilizan directa o indirectamente fuentes judías, o la aparición de judíos como personajes o del judaísmo como tema en obras escritas por cristianos; en este último grupo tendríamos que incluir también la literatura antijudía y anticonversa (en general, en las obras antijudías medieva-

1 "Huellas judías en la literatura española", Luces y sombras de la Judería europea (siglos XI-XVIII) (Pamplona: Gobierno de Navarra, 1996), pp. 87-118. 
les y de los Siglos de Oro no se distingue entre verdaderos judíos y conversos $\mathrm{o}$, mejor dicho, se considera sistemáticamente a todo converso como falso converso y, por tanto, judío disimulado).

Por lo que respecta a la literatura escrita por conversos, importa diferenciar entre las obras de conversos de primera generación y de descendientes de conversos, y ello por razones evidentes: un converso de primera generación es alguien que ha sido educado en una religión (la judía) y adopta luego otra (la cristiana); y esa educación primera implica no sólo unas creencias y prácticas estrictamente religiosas, sino un universo cultural, el acceso a unas lecturas - recuérdese que el judaísmo es ante todo una religión basada en la palabra escrita- y hasta unos usos y costumbres que a veces resulta difícil desarraigar, incluso en el caso de conversiones sinceras; en cambio, el descendiente de conversos - aunque sea consciente de sus orígenes- puede no haber recibido ni un ápice de esa formación judaica y ser totalmente ignorante del complejo mundo cultural del judaísmo. Al hablar de conversos de primera generación frente a descendientes de conversos, estamos haciendo sobre todo una distinción en la base cultural y de mentalidad de unos y de otros.

Tanto en uno como en otro caso, todavía hay otra distinción que hacer (aunque es cierto que resulta más operativa para la literatura de los siglos XVI y XVII que para la medieval): diferenciar las obras escritas por autores conversos (o sus descendientes) de los cuales no nos consta que después de su conversión siguieran apegados a las prácticas y creencias de su antigua religión, y las escritas por conversos criptojudíos. La distinción es importante, precisamente porque no siempre se ha tenido en cuenta en los estudios históricos y literarios sobre autores conversos y con frecuencia se ha abusado de la identificación descendiente de conversos $=$ converso $=$ criptojudio $^{2}$.

Por tanto, podríamos tipificar las influencias judías en la literatura castellana de acuerdo con el siguiente esquema:

1. Obras escritas por judíos.

2. Obras escritas por cristianos

2 Son numerosas - $-\mathrm{y}$, a veces, disparatadas - las lecturas "judías" de obras escritas por conversos de los que no nos consta que hubiesen tenido ninguna formación judía. Caso paradigmático es el de La Celestina desde el descubrimiento de los orígenes conversos de Fernando de Rojas: un excelente estado de la cuestión es el de Nicasio SALVADOR Miguel, "El presunto judaísmo de La Celestina", The Age of the Catholic Monarchs, 1474-1516. Literary Studies in Memory of Keith Whinnom (Liverpool: Liverpool University Press, 1989), pp. 162-177. 
2.1. Participación de judíos en empresas culturales cristianas (obras científicas, romanceamientos bíblicos).

2.2. Obras cristianas que utilizan, directa o indirectamente, fuentes judías (Biblia, influencia de temas y géneros de la literatura judía diaspórica).

2.3. El judío como personaje en obras escritas por cristianos.

2.4. Lo judío y el judaísmo como tema (en obras legislativas, históricas, literarias). La literatura antijudía.

3. Obras escritas por conversos

3.1. Obras de conversos de primera generación.

3.2. Obras de autores criptojudíos.

3.3. Obras de autores cristianos descendientes de conversos.

Todavía queda una matización que hacer, ésta de carácter cronológico: no podemos considerar las influencias judías en la literatura castellana medieval de la misma manera en los primeros siglos (desde el Cantar de mio Cid hasta el siglo XIV) que en el XV. Desde la oleada de asaltos a juderías de 1391 hasta la expulsión por los Reyes Católicos en 1492 el panorama de la presencia judía en la sociedad hispánica cambia: los ataques físicos y verbales, las matanzas, las campañas de predicación de franciscanos y dominicos, las disputas religiosas como la de Tortosa de 14131414, la legislación cada vez más restrictiva, van creando un clima coactivo que aboca a muchos judíos a la conversión más forzada que sincera ${ }^{3}$. El cada vez mayor número de conversos introduce en la sociedad hispánica del siglo $\mathrm{xv}$ un elemento nuevo, que cambia radicalmente las relaciones entre cristianos y judíos y que desembocará en el nacimiento de los estatutos de limpieza de sangre, la creación de la Inquisición nueva en 1480 y, finalmente, la expulsión, que no hará sino provocar nuevas conversiones forzadas y acrecentar el problema que pretendía solucionarse con tan drástica medida: la presencia en la sociedad de esos malos cristianos herejes, en la mentalidad de la época- que son aquellos conversos que sólo externamente adoptaron el cristianismo.

Así, no es lo mismo hablar del judío como personaje literario o de la literatura antijudía en el siglo xIII que en el xv, porque entre un siglo y otro muchas cosas han cambiado en la situación social y en las mentalidades.

3 Una síntesis de todos estos hechos puede verse en los capítulos correspondientes de Yitzhak BAER, Historia de los judíos en la España cristiana (Madrid: Altalena, 1981), 2 vols.; el libro es traducción castellana (por José Luis Lacave) del original publicado en hebreo en 1945; hay reedición española más reciente (Barcelona: Riopiedras, 1997). 


\section{LA LITERATURA ESCRITA POR JUDÍOS}

Lógicamente, no voy a ofrecer aquí un repaso exhaustivo de todas las posibilidades de influencias judías en la literatura castellana medieval que se desprenden de la tipología antes propuesta. Me centraré, más bien, en algunos aspectos del punto primero, es decir, las escasas muestras que nos han llegado de literatura medieval castellana escrita por judíos, con especial atención a los aspectos en que esa literatura interacciona con la de los cristianos, bien sea por cuestión de fuentes, de recursos literarios o de transmisión y difusión.

Tenemos noticia de cuatro poemas escritos en castellano por autores judíos en la Edad Media. Son los siguientes:

1) El largo poema sapiencial y moral que suele titularse Proverbios morales, dedicado por un judío llamado Sem Tob de Carrión al rey don Pedro I de Castilla ha. $1350^{4}$. Consta de más de setecientas estrofas (que varios editores han considerado cuartetas heptasilábicas con rima alterna, aunque otros las han entendido como pareados alejandrinos con rima interna, aspecto sobre el que volveremos más adelante) y nos han llegado en cinco manuscritos del siglo Xv —uno de ellos aljamiado-, además de otros testimonios parciales o indirectos.

2) Unas Coplas de Yoçef, al parecer del siglo XIV, de las cuales nos han llegado dos fragmentos en sendos manuscritos aljamiados medievales y una versión al parecer completa en otro, también aljamiado, quizás del siglo XVI. En su versión más cabal el texto tiene más de trescientas cuartetas alejandrinas con rima zejelesca (con vuelta en Yoçef) y rima interna entre los primeros hemistiquios ${ }^{5}$. El tema es una narración de la historia

4 La edición anotada y con estudio más reciente es la de Paloma DíAz-MAS y Carlos Mota, eds. Sem Tob de Carrión, Proverbios morales (Madrid: Cátedra, 1998). El primero en intentar una edición crítica (aunque sin notas explicativas) del poema fue Ignacio González Llubera, ed. Santob de Carrión, Proverbios morales (Cambridge: Cambridge University Press, 1935). Otras ediciones posteriores son las de Agustín GarCía Calvo, ed. Don Sem Tob, Glosas de Sabiduría o Proverbios morales y otras rimas (Madrid: Alianza, 1974); Sanford SHEPARD, ed. Sem Tob, Proverbios morales (Madrid: Castalia, 1985); Theodore A. Perry, ed. Santob de Carrión, Proverbios morales (Madison: Hispanic Seminary of Medieval Studies, 1986) y, más recientemente, la de Marcella CiCERI, ed. Sem Tob de Carrión, Proverbios morales (Módena: Mucchi, 1998). Una guía bibliográfica fundamental de ediciones y estudios sobre el poema es la de John Max ZEMKE, Critical Approaches to the Proverbios morales of Shem Tov de Carrión: An Annotated Bibliography (Newark [Delaware]: Juan de la Cuesta, 1997).

5 Un primer fragmento lo publicó Moïse SCHWAB, "Quatrains judéo-espagnols", Revue Hispanique, 23 (1910), pp. 321-326. Posteriormente Ignacio GonZález LlubERA editó 
bíblica de José que se cuenta en Génesis 37-50, con abundantes elementos procedentes de la comentarística rabínica midrášica ${ }^{6}$.

3) Un poema de tema bíblico que suele titularse El pecado original y que narra la creación de la mujer y el pecado de nuestros primeros padres (Génesis 2:21-23), también con incorporación de algunos elementos midrášicos. Nos ha llegado en un manuscrito en caracteres latinos en compañía de otros dos poemas cristianos ${ }^{7}$ y ha pervivido hasta el mismo siglo xx en la tradición oral de los judíos de Marruecos, quienes lo usaban como canto paralitúrgico en la conmemoración luctuosa de Tišśá beab, que recuerda la destrucción del Templo de Jerusalén. Su métrica, un tanto irregular - seguramente como consecuencia de los avatares de la transmisión escrita y oral- parece indicar que en su origen el poema estuvo en cuartetas de versos largos monorrimos.

4) Un poema de contenido moral que se ha titulado Lamentación del alma ante la muerte ${ }^{8}$, aparecido en una carta de 1797 dirigida al erudito

otro fragmento más amplio en "Fragmentos de un poema judeo-español medieval", Revue Hispanique, 81 (1933), pp. 421-433 y, sobre todo, en Coplas de Yoçef. A Medieval Spanish Poem in Hebrew Characters (Cambridge: The University Press, 1935). Con posterioridad se ha descubierto lo que parece ser una versión cabal del mismo poema: véase la noticia en Iacob M. HAsś́N, "Una versión ¿̇completa? de las Coplas de Yoçef publicadas fragmentariamente por González Lluberan, I Congreso Internacional Encuentro de las Tres Culturas (Toledo: Ayuntamiento, 1983), pp. 283-288; y la transcripción del texto (sin notas ni comentario) en Moshe LAZAR, Joseph and bis Breethren. Three Ladino Versions: Poema de Yosef, Coplas de Yosef ha-Saddiq, Sefer ha-Yasar (Culver City: Labyrinthos, 1990), pp. 1-96; sobre este último, véase la reseña de Samuel G. ARMisteAD, "Three Jewish-Spanish Joseph Narratives", Romance Philology, 49 (1995), pp. 34-52.

6 Recuérdese que el midráš es un tipo de comentarística rabínica de la Biblia que, junto con el Talmud, constituye la llamada ley oral de la tradición judía; incorpora abundantes elementos míticos y legendarios y es usado con frecuencia como fuente en obras literarias judías. Como introducción a la ley oral puede verse H. L. STRACK y Günter STEMBERGER, Introducción a la literatura talmúdica y midrásica, ed. española preparada por Miguel PÉrez FERnÁNDeZ (Estella: Editorial Verbo Divino, 1996, 2." ed.).

7 Lo publicó Carmen Pescador Del Hoyo, "Tres nuevos poemas medievales", Nueva Revista de Filología Hispánica, 14 (1960), pp. 242-250. Es fundamental el estudio de Iacob M. HASSÁN, “¿Adóte Adán/Dónde estás Adán? en las literaturas judeoespañola e hispanojudía", Hispanic Medieval Studies in Honor of S.G. Armistead (Madison: Hispanic Seminary of Medieval Studies, 1992), pp. 163-172.

8 Lo descubrió Jesús Antonio CID, "Lamentación del alma ante la muerte: Un nuevo poema medieval judeo-español", Poesía estrófica. Actas del Primer Congreso Internacional... (Madrid: Universidad Complutense-Instituto de Cooperación con el Mundo Árabe, 1991), pp. 43-70; y lo estudió más detalladamente en su artículo "Lamentación del alma ante la muerte. Nuevo poema medieval", Estudios de Folklore y Literatura dedicados a Mercedes Diaz Roig (México: El Colegio de México, 1992), pp. 729-791. 
hebraísta dieciochesco Tomás Antonio Sánchez por su amigo el inquisidor Valenciano Nicolás Rodríguez Laso, quien a su vez lo había copiado de "un Orario de un judío, intitulado Reglas, manuscrito" que se conservaba en la biblioteca del monasterio jerónimo de San Miguel, en Valencia. La composición está en cuartetas zejelescas de verso corto y presenta restos evidentes de un acróstico alfabético hebreo, que indica que debió de estar originalmente escrita en aljamía hebraica (aunque el manuscrito del que copió Rodríguez Laso era en caracteres latinos). Por lo que respecta a su contenido, se trata de una meditación sobre la pequeñez del hombre ante la muerte, tema muy frecuente en la poesía penitencial judía.

Una mera reflexión sobre los modos de transmisión y difusión de estos textos, sobre sus rasgos formales y su contenido, ponen de manifiesto hasta qué punto son producto de una interacción multicultural y ejemplo de la influencia recíproca entre la cultura cristiana y la judía en la Edad Media castellana.

\section{II.1. Destinatarios y vias de transmisión de la poesía judia medieval en lengua romance}

Por lo que se refiere a la forma como se transmitieron esos textos, sus destinatarios y usuarios, las características de las fuentes en que nos han llegado resultan bien significativas de la comunicación cultural entre judíos y cristianos:

a) Los Proverbios morales son un poema dirigido por un judío a un rey cristiano, a quien ofrece una serie de reflexiones morales y dichos sapienciales que sirven de aderezo y ornato a lo que, en definitivas cuentas, resulta ser un poema petitorio: los versos "así vós fincastes d'él para muncho turar / e fazer lo que él cobdiçiaba librar: // como la debda mía, que a vós muy poco monta, / con la cual yo podría bevir sin toda onta" (estrs. 6-7) y «e la meçed qu'el noble, su padre, prometió, / la terná, como cumple, al Santob el judión (estr. 725) nos ponen sobre la pista de que el rey anterior había dejado pendiente una deuda con el judío ${ }^{9}$, cuya restitución éste reclama.

Por tanto, al parecer se trata - en su origen- de un poema muy circunstancial. Pero su difusión y su uso fueron mucho más amplios y di-

9 Sobre el carácter de esa deuda ha tratado Agustín García Calvo (ed. cit. en nota 4), p. 162, quien se inclina por entender que era la devolución de un empréstito que Sem Tob había hecho al rey; sin embargo, nótese que se refiere a ella como merçed, que era el premio que se daba como compensación de un servicio; de ser así, la debda de 7a sería más moral que estrictamente material: al joven rey correspondía compensar los servicios prestados por Sem Tob a su padre, Alfonso XI. 
versos de lo que esa circunstancia hacía esperar, como lo demuestran tanto los manuscritos en que el poema nos ha llegado como varios testimonios indirectos. Sabemos, por ejemplo, que la vigencia de los Proverbios morales se extendió más allá de su siglo, como demuestra el hecho de que los manuscritos conservados sean del Xv; es decir, entre un siglo y siglo y medio después de su composición.

El poema fue, desde luego, conocido y apreciado entre cristianos, que valoraron su contenido moral y sapiencial. Resulta significativo al respecto que en uno de los manuscritos ( $M$, de la Biblioteca Nacional de Madrid), los Proverbios aparezcan en compañía de otras obras morales como son una serie de dichos de sabios, el Libro llamado consegero de los consejos y el Libro de la consolación de España. En otros manuscritos ( $N$, que fue de Rodríguez Moñino y hoy está en la Biblioteca de la Real Academia Española; $E$, de la Biblioteca de El Escorial) aparece entre obras de diverso contenido, entre las que se cuentan el Sermón trobado de Íñigo de Mendoza, el Tratado sobre la fe católica de Alonso Fernández de Ocaña, la Doctrina cristiana de Pedro de Veragüe o la Revelación de un hermitaño (pero también las Coplas de Mingo Revulgo, unas Coplas al rey don Fernando de Alfonso Álvarez de Villasandino o la Danza general de la Muerte); es decir, el poema escrito por el judío se acompaña en el volumen de otras obras no sólo escritas por cristianos, sino de algunas de directo contenido religioso. Lo que primó en la consideración de sus lectores cristianos fue el contenido moral del poema, independientemente de la distinta fe religiosa de su autor; como el propio Sem Tob había escrito (estr. 64):

$$
\begin{aligned}
& \text { non val el açor menos por nasçer de mal nido, } \\
& \text { nin los enxemplos buenos }
\end{aligned}
$$

Y precisamente son estos versos los que cita el Marqués de Santillana cuando, en su Carta-Probemio al Condestable de Portugal menciona a Sem Tob de Carrión como autor de "asaz comendables sentençias". En la misma línea apunta un prólogo anónimo que acompaña a nuestro poema en el manuscrito $M^{10}$, donde su autor (que al parecer había escrito unas glosas o comentarios explicativos de los Proverbios morales que no se nos han conservado) afirma que "las dichas trobas son muy notable escritura, que todo omre la deviera decorar", es decir, que todos las deberían aprender de memoria.

10 El prólogo puede verse en nuestra edición citada en nota 4 supra, pp. 245249. Lo habían editado con anterioridad GONZÁlez LLUBERA, pp. 61-63 y PERRY, pp. $168-171$. 
De que el poema se decoró no cabe duda: probablemente de memoria se lo sabía el anónimo autor de un Libro del regimiento de señores, de hacia mediados del siglo $\mathrm{Xv}^{11}$, que en uno de sus pasajes cita - prosificadas - una serie de estrofas de nuestro poema para ejemplificar la idea de que el hombre, cuanto más tiene, más quiere. Y, desde luego, de memoria se lo sabía Ferrán Verde, un mercader converso procesado por la Inquisición, gracias a cuya memoria nos ha llegado el quinto manuscrito de los Proverbios morales ${ }^{12}$.

El proceso de Ferrán Verde se inició en Sigüenza en 1492 y cuatro años más tarde el procesado aún estaba en la cárcel, aunque finalmente salió absuelto. Una de las acusaciones del tribunal es que "con la afición que tiene a la dicha ley de Moisé ha tenido lecturas reprovadas y leído en ellas, especialmente en el Génesi et en una obra de rabí Sonto la cual aprovava por buena. Para demostrar que la "obra de rabí Sonto" no es ni herética ni constituye lectura reprobable para un cristiano, Ferrán Verde argumenta que si "las aprovava por buenas entiéndase de buenos castigos y enxemplos, porque desa misma suerte provava y leía en las obras de fray Iñigo de Mendoza y de Juan de Mena y aún en la Pasión Trobada e otras muchas de grant devoción e consolación y exemplo y doctrina, y en los Evangelios y Flos santorum y en la Vida de los santos padres.....

Indudablemente, el procesado acumula obras piadosas muy cristianas y sin sombra de herejía para demostrar lo inocuo de su lectura de los Proverbios morales (iy del Génesis!); pero nótese que en compañía de obras de ese estilo aparece nuestro poema en algunos de los manuscritos contemporáneos del proceso inquisitorial. En todo caso, Verde presenta en 1496 a través de su procurador una prueba de descargo: para que se vea que no hay en ellas rastro de herejía, ha copiado en papel todas las estrofas que ha podido recordar del poema: "todas las que supiese et a la memoria me viniesen. Su memoria le dio para recordar 219 estrofas, en un orden que - como podía esperarse- difiere del de todos los otros manuscritos.

Hasta aquí la difusión y el uso que los Proverbios morales debieron de tener entre cristianos. De que el poema se copió también para uso de judíos tenemos una prueba fehaciente: uno de los manuscritos (el $C$,

11 La cita de los Proverbios en ese libro la descubrió John Max ZEMKE, "A Neglected Fragment of Shem Tov's Proverbios morales", La Corónica, 17 (1988-89), pp. 76-89. El libro perteneció a la biblioteca de los Condes de Haro y se encuentra actualmente en la Biblioteca Nacional de Madrid.

12 El testimonio lo dio a conocer Luisa LóPEZ Grigera, "Un nuevo códice de los Proverbios morales de Sem Tob", Boletín de la Real Academia Española, 56 (1976), pp. 221-281. 
conservado en la Universidad de Cambridge) es aljamiado; si el texto se copió en aljamía hebraica fue, evidentemente, para uso exclusivo de judíos.

El manuscrito de Cambridge - al que faltan varias páginas- parece destinado a un uso personal: es un pequeño cuadernito cuyas hojas no superan los $10 \mathrm{~cm}$. de lado, apto para sostenerse abierto en una sola mano y para ser guardado en un bolsillo o - como era usual en la época- en la manga del vestido. Junto a los Proverbios morales, hay unas cuarenta estrofas de otro de los poemas judíos medievales que hemos mencionado: las Coplas de Yoçef ${ }^{13}$.

No sabemos cuál sería el uso que su destinatario judío daría al poema. Pero teniendo en cuenta la compañía en que aparece en el manuscrito (un poema sobre el José de la Biblia, tema que tradicionalmente los judíos han considerado vinculado a la festividad de Purim) y que el contenido moral y sapiencial de la obra de Sem Tob de Carrión viene a coincidir con algunos de los tópicos de la poesía penitencial que se canta o recita en determinadas ocasiones litúrgicas, no sería raro que en el pequeño manuscrito aljamiado se hubiesen reunido dos o más poemas que para los judíos tenían una función paralitúrgica en ciertas festividades del año ${ }^{14}$. Eso, por supuesto, independientemente de que los Proverbios morales se compusieran en su origen para dedicarlos a un rey cristiano, en cuya corte se leerían.

b) También significativa es la difusión que parecieron tener las medievales Coplas de Yoçef: aparte del manuscrito de Cambridge, donde aparece en compañía de la obra de Sem Tob de Carrión, se conocía otro fragmento de lo que parecía ser el mismo poema, aparecido en las hojas de guarda de un libro de la Biblioteca Nacional de París. Sólo recientemente se ha descubierto lo que parece ser una versión cabal del poema ${ }^{15}$ : un manuscrito también aljamiado, copiado al parecer en el siglo xvI, lo cual documentaría la difusión y pervivencia del poema entre los judíos expulsos.

El manuscrito se descubrió nada menos que en el centro mismo de la cristiandad católica: la Biblioteca Vaticana. Y - también significativamentepertenece al fondo Neophyti de esa biblioteca. El fondo proviene ${ }^{16}$ de

13 Fue ese texto de las Coplas de Yoçef el que publicó González Llubera en su artículo y libro citados en nota 5 .

14 Recuérdese que en la religión judía, tan importante o más que el culto público sinagogal y que la práctica personal, es la celebración en el ámbito doméstico. Para la práctica familiar del šabat y las festividades litúrgicas se ha desarrollado toda una paraliturgia doméstica en la que tienen perfecta cabida este tipo de composiciones poéticas en lengua vulgar, aptas para ser cantadas por toda la famlia en esas ocasiones. Por ejemplo, es uso abundantemente documentado entre los sefardíes.

15 Véanse los datos que ofrecemos en nuestra nota 5 supra. 
un colegio de neófitos romano especialmente dedicado a la reeducación de cristianos apóstatas que volvían a la verdadera fe. No sabemos cómo llegó el manuscrito aljamiado de las Coplas de Yoçef a ese colegio de neófitos, pero no resulta imposible que hubiese pertenecido a algún converso del judaísmo. La acusación a Ferrán Verde de haber tenido "lecturas reprobadas" se cerraría así circularmente en el desconocido poseedor del manuscrito del poema sobre José.

c) Y también "lectura reprobada" de un converso - probablemente, éste sí, criptojudío- parece haber sido el cuarto de los poemas judíos medievales antes mencionados: la Lamentación del alma ante la muerte.

Como ya hemos dicho, el texto que conocemos lo copió Nicolás Rodríguez Laso de un manuscrito que se conservaba en la biblioteca del monasterio valenciano de San Miguel de los Reyes. Ese monasterio jerónimo fue fundado en 1546 por el Duque de Calabria (a la sazón, virrey de Valencia), quien dotó espléndidamente su biblioteca. Pero fueron a parar a ella fondos de otros monasterios jerónimos.

Recuérdese que la orden jerónima fue desde finales del siglo Xv un refugio no sólo de conversos, sino directamente de criptojudíos, hasta los procesos inquisitoriales de 1485-1490 ${ }^{17}$. El "orario" que más de dos siglos y medio después fue casualmente a manos de otro inquisidor, Rodríguez Laso, probablemente sería un resto de esa presencia criptojudía en la orden.

Cabe preguntarse para qué utilizó el desconocido criptojudío el poema de La lamentación del alma ante la muerte. Su propio contenido nos sugiere la respuesta: se trata de una reflexión moral sobre la pequeñez del hombre, la enormidad del pecado y la inminencia de la muerte, todos ellos tópicos usuales en la poesía judía para los yamim nora 'ím o 'días temerosos' dedicados a la penitencia, que van desde el inicio del año judío (Roš hašaná) hasta el día de la expiación o Yom Kippur. Poemas similares conocemos tanto en hebreo, para la celebración litúrgica sinagogal, como - entre los sefardíes - en lengua vulgar, destinados a la paraliturgia doméstica o a la práctica personal. Si el texto que copió Rodríguez Laso formaba parte de un "orario" hoy perdido que, según su propio testimonio, "después de varias oraciones trahe esas coplas", ese volumen sería muy probablemente un orden de las oraciones de determinadas ocasiones litúrgicas; o, mejor dicho, la transcripción a caracteres latinos de lo que debió de ser una compilación de textos en caracteres hebreos: recuérdese que, como ya hemos dicho más arriba, el poema

16 Según nos comentó la profesora Laura Minervini, de la Universidad de Nápoles.

17 Datos sobre esta presencia de criptojudíos en la orden jerónima y bibliografía al respecto puede verse en el artículo de Cid de 1992 citado en nota 8, pp. 771-791. 
presenta muestras evidentes de que los inicios de sus estrofas formaban un acróstico alfabético hebreo, procedimiento nemotécnico usual en la poesía en lengua hebrea (desde la Biblia) y muy utilizado por los sefardíes expulsos en poemas en judeoespañol.

d) Muy alejado de este mundo de heterodoxia se nos muestra el manuscrito en el cual nos ha llegado el poema sobre El pecado original. Se trata de un par de hojas de papel en las que se han copiado cuidadosamente con buena letra de finales del siglo XIV o principios del XV tres poemas de tema religioso: el primero es, precisamente, el que aquí comentamos, que comienza "El Dio alto que los çielos sostiene"; le sigue una composición un tanto insólita en el ámbito de las letras medievales castellanas, aunque no rara en otras tradiciones literarias europeas, como la francesa o la provenzal: un canto de cruzada que suele titularse $A y$, Iherusalem. La pequeña colección se cierra con una versión rimada de Los diez mandamientos cristianos (que son diferentes de los judíos, sobre todo los dos primeros).

La compañía en que el poema aparece es, por tanto, la de dos composiciones cristianas de contenido religioso. Sin embargo, Iacob M. Hassán ha demostrado ${ }^{18}$ que El pecado original es una composición judía. Lo avalan rasgos lingüísticos como el uso de la forma el Dio en vez de Dios, habitual entre los judíos desde la Edad Media; la expresión pueblo elegido; alusiones a la Ley, que es la forma habitual para referirse a la Torá entre los judíos de origen hispánico. Rasgos estilísticos como el uso de la expresión el Dio alto, muy habitual en la poesía sefardí postexílica. Rasgos formales, como restos de acróstico alfabético; y el detalle de que el fruto del pecado sea precisamente el higo (y no la manzana tradicional en la iconografía cristiana, o cualquier otro fruto), que proviene de la comentarística rabínica. Además, el poema ha permanecido vivo hasta el mismo siglo Xx en la tradición oral de los sefardíes de Marruecos, donde se consideraba canto propio de la celebración luctuosa de Tiš́á beab, que conmemora de caída de Jerusalén en manos de los infieles y la destrucción del primer y segundo Templos.

\section{II.2. El Ay, Iherusalem como testimonio indirecto de una tradición judia}

Precisamente sobre la caída de Jerusalén en manos de infieles trata el segundo poema de ese manuscrito, $A y$, Iberusalem.

\footnotetext{
18 En su artículo citado en nota 7 más arriba.
} 
Se trata de un poema en 22 estrofas que combinan dodecasílabos y hexasílabos con rima zejelesca AAbbv con vuelta en Iberusalem. Su fecha de composición se vincula a alguno de los concilios celebrados en Lyon con motivo de las Cruzadas ${ }^{19}$.

Por sus recursos estilísticos se ha denominado planto de cruzada: empieza con un llamamiento del maestre de Acre pidiendo auxilio a la Cristiandad porque la ciudad santa está cercada por los infieles (se entiende, los turcos mamelucos), continúa aludiendo a una fallida expedición cristiana en socorro de la ciudad y acaba con un llamamiento a unirse a la Cruzada o apoyarla; en sus estrofas $17-21$ se desarrolla una lamentación por la caída de Jerusalén en manos de los infieles, recreándose en la descripción de las profanaciones de los lugares santos y las vejaciones a la población perpetradas por aquéllos. Es precisamente el tono de lamentación o treno, unido a recursos estilísticos típicamente endechescos (paralelismo, seguramente uso de estribillo en el que se incluiría la guaya $A y$, Iherusalem), lo que ha justificado el apelativo de planto de cruzada.

Naturalmente, el poema toma una serie de elementos que en último término provienen de las Lamentaciones por antonomasia: las del libro bíblico de Jeremías. Pero cabe preguntarse si las toma directamente del libro bíblico o de una tradición inspirada en él, que puede ser precisamente la judía.

Varios rasgos formales y de contenido sugieren una presunta base judía en este poema de temática e intención tan plenamente cristiana: para empezar, el uso de las rimas zejelescas, de origen semítico, que no comienzan a utilizarse en la poesía castellana hasta el siglo XIV (el de nuestro poema sería, por tanto, el primer uso de la estrofa zejelesca en la poesía cristiana). Para seguir, el detalle de que el poema es acróstico alfabético: con la primera letra de cada estrofa se forma el alfabeto latino, pero el número de estrofas (y de letras) es 22, el mismo que en el alfabeto hebreo ${ }^{20}$; este procedimiento del acróstico alfabético es habitua-

19 Eugenio ASENSIO propone la fecha de 1274 en su fundamental artículo " $A y$, Iherusalem! Planto narrativo del siglo XII", Nueva Revista de Filología Hispánica, 14 (1960), pp. 251-270; reeditado en su libro Poética y realidad en el cancionero peninsular de la Edad Media (Madrid: Gredos, 1970), pp. 263-292. Mientras que Alan DEYERMOND defiende que se trata del concilio de Lyon de 1245 en "iAy Jberusalem!, estrofa 22: "traductio y tipología", Estudios ofrecidos a Emilio Alarcos Llorach con motivo de sus XXV años de docencia en la Universidad de Oviedo (Oviedo: Universidad, 1976), pp. 283-290.

20 El primero en hacerlo notar fue Henk DE VRIEs, "Un conjunto estructural: el Poema tríptico del nombre de Dios en la ley, Boletín de la Real Academia Española, 51 (1971), pp. 305-325; vuelven a ello Cid en su artículo de 1992 citado en nota 8 pp. 762-764 y Enzo FranCHINI, "Ay, Iherusalem, ¿Una Canción de Cruzada Castellana?", 
lísimo en la poesía hebrea (desde la Biblia, donde, por ejemplo, algunos salmos están compuesto así) y en la judía en general (es muy usual, por ejemplo, en el género de las coplas sefardíes ${ }^{21}$ ). Por otra parte, el tema de la toma y profanación de Jerusalén es usual en la poesía judía ya desde la Biblia ${ }^{22}$, hecho propiciado porque existe una conmemoración litúrgica destinada al recuerdo de esos hechos: precisamente Tiš́á beab, la misma festividad del calendario judío en que los sefardíes de Marruecos cantaban El pecado original que acompaña al Ay, Iherusalem en el manuscrito.

El que ambos poemas aparezcan juntos en el mismo manuscrito y las coincidencias del planto de cruzada con recursos y temas de la poesía judía nos sugieren inquietantes relaciones entre la poesía medieval judía y la cristiana. Quizás el anónimo compositor — sin duda cristiano y que escribe para destinatarios cristianos, que son los únicos que podían estar interesados en apoyar la Cruzada - tuvo en cuenta modelos judíos. A la hora de tratar un tema como el de la caída de Jerusalén en manos de infieles se encuentra sin modelo en las letras castellanas de su época; y nada tendría de extraño que recurriese al modelo de una poesía en la que la toma de Jerusalén tenía una larga y ancha tradición: precisamente, la judía. Así, la adopción de una forma métrica insólita en la poesía cas-

Actas do IV Congresso da Associaçao Hispanica de Literatura Medieval (Lisboa: Cosmos, 1993), vol. II, pp. 343-348. El acróstico sigue el orden alfabético hasta la estrofa 20 , mientras que la 21 y la 22 forman el anagrama $D Q$, iniciales de Dios [lo] quiere, que es el equivalente castellano del lema de cruzada Deus volet.

21 Para este género poético sefardí - en gran medida heredero y continuador de la poesía judía medieval en lengua romance que estamos viendo aquí- puede consultarse la panorámica de Elena ROMERO, La creación literaria en lengua sefardi (Madrid: Mapfre, 1992), pp. 141-176; y la antología de textos de Elena ROMERO (con introducción de Iacob M. HASSÁN), Coplas sefardies: Primera selección (Córdoba: El Almendro, 1991). Específicamente sobre los esquemas estróficos de las coplas, Elena ROMERo, "Formas estróficas de las coplas sefardíes", Poesía estrófica. Actas del Primer Congreso Internacional... (Madrid: Universidad Complutense-Instituto de Cooperación con el Mundo Árabe, 1991), pp. 259-278.

22 Y en la sefardí postexílica hay todo un ciclo de quinot ('endechas') en judeoespañol para la ocasión. Algunas de ellas, procedentes de libros y manuscritos aljamiados de Oriente, las editan lacob M. HASSÁN y Elena ROMERO, "Quinot paralitúrgicas: edición y variantes", Estudios Sefardies, 1 (1978), pp. 3-57. De la tradición sefardí de Marruecos han editado algunos textos Manuel ALvar, Endechas judeo-españolas, ed. refundida y aumentada (Madrid:CSIC, 1969), núms. VIIa-b; Arcadio DE LARREA PalaCín, Cancionero judio del norte de Marruecos: canciones rituales hispano judias (Madrid: CSIC, 1954), pp. núms. 169-171; Juan MarTínez Ruiz, "Poesía sefardí de carácter tradicional (Alcazarquivir)", Archivum, 13 (1963), pp. 79-215, núm. XX; y yo misma, Temas y tópicos en la poesía luctuosa sefardi (Madrid: Universidad Complutense, 1982), pp. 166-185. 
tellana del siglo xiII y el uso del acróstico alfabético con el mismo número de letras que el hebreo podría explicarse porque el poeta elabora un contrafactum cristianizado sobre la base de un poema judío, seguramente no en hebreo, sino en lengua romance y -en su origen - aljamiado (lo que explicaría el uso del acróstico).

No se nos han conservado poemas judíos medievales sobre la caída de Jerusalén en castellano, pero el tema es fecundo en la literatura sefardí tras la expulsión ${ }^{23}$. El Ay, Iberusalem parece un testimonio indirecto de que ese tipo de poemas existió también antes de la expulsión y su presencia entre los sefardíes postexílicos no sería una novedad, sino continuación de una tradición de cuño medieval.

El manuscrito de los tres poemas resulta ser, por otra parte, muestra de un sincretismo cultural muy propio de la Castilla medieval. Aunque sin duda destinado al uso de cristianos, se abre con un poema judío que narra un pasaje del Génesis que es precisamente el origen de los males de la Humanidad: El pecado original; continúa con un poema de contenido plenamente cristiano (el planto de cruzada $A y$, Iherusalem), pero que parece inspirarse en un modelo judío; y se cierra con una muy cristiana invitación a evitar el pecado, causa de todos los males, por la vía de cumplir los mandamientos del Cristianismo (Los diez mandamientos).

\section{LA INTERCULTURALIDAD EN LOS RASGOS FORMALES}

Hasta ahora nos hemos centrado en aspectos de difusión y contenido que revelan la intercomunicación y mutua inspiración de la poesía compuesta por cristianos y la compuesta por judíos en la Castilla medieval. Comentaremos ahora algunos rasgos formales que parecen apuntar en la misma dirección.

Al hablar del $A y$, Iherusalem ya hemos señalado algunos rasgos formales que parecen de inspiración judía, como el acróstico o las rimas zejelescas; a ello habría que añadir algún resto del tipo de rima que suele llamarse homoioteleuton. En esencia, se trata de una rima que resulta no ser ni consonante ni asonante según los parámetros habituales en la

23 No sólo en las quinot sefardíes mencionadas en la nota anterior, que son de los siglos XVIII al XX. Recientemente Eleazar GUTWIRTH ha dado a conocer dos fragmentos, muy deteriorados, de quinot en lengua romance encontrados en la Guenizá de El Cairo, que serían probablemente del siglo xvI, es decir, anteriores a la tradición sefardí documentada y, por tanto, un eslabón intermedio entre la poesía judía medieval en castellano y la sefardí; véanse sus artículos "A Judeo-Spanish planctus from the Cairo Guenizah", Romance Philology, 49 (1996), pp. 420-428; y "A Judeo-Spanish endecha from the Cairo Genizah", Mediterranean Language Review, 6-7 (1993), pp. 113-120. 
métrica castellana, porque no se cuenta desde la última vocal acentuada del verso; lo que importa es la identidad de los últimos sonidos y, esencialmente, de la última sílaba, aunque ésta puede ser rebasada.

Este tipo de rima es habitual en la poesía árabe y hebrea y, por influencia de ésta, la usan los autores judíos: es frecuentísima en los Proverbios morales de Sem Tob, donde se estudió por vez primera ${ }^{24}$, se da también en La lamentación del alma ante la muerte y en las Coplas de Yoçef y -aunque no es posible saber si se trata de homoioteleuton o de rimas imperfectas - hay alguna muestra en El pecado original.

Otras influencias formales son a la inversa: de la poesía castellana culta medieval a los autores judíos. No por casualidad, tanto la Lamentación del alma ante la muerte como las Coplas de Yoçef y los Proverbios morales de Sem Tob adoptan la base heptasilábica en sus versos. El verso de la poesía culta y sabia contemporánea (los tres poemas son, al parecer, del siglo XIV) es precisamente el de la cuaderna vía, de base también heptasilábica, ya que es un alejandrino con cesura, cada uno de cuyos hemistiquios tiene, lógicamente, siete sílabas.

Si la Lamentación del alma adopta el heptasilabo en estrofas zejelescas, las Coplas de Yoçef optan directamente por lo que se ha llamado cuaderna vía anómala: una estrofa de cuatro alejandrinos con cesura en la cual los primeros tres versos son monorrimos y el cuarto tiene una rima de vuelta con el resto de las estrofas; la cuaderna vía anómala del poema tiene además el artificio añadido de poseer rima interna entre los primeros hemistiquios de cada verso.

Precisamente es esa forma métrica de las Coplas de Yoçef-que, recuérdese, acompañan a los Proverbios morales en el único manuscrito aljamiado de éstos- una de las razones ${ }^{25}$ que nos inclina a entender la métrica de Sem Tob como pareados alejandrinos con cesura y rima entre los primeros hemistiquios del verso. Por otro lado, esa práctica de rimar los primeros hemistiquios entre sí es frecuente en la poesía hebrea. Con ello, el verso de Sem Tob resulta ser una síntesis de usos métricos vigentes en la poesía castellana cristiana de su época y en la tradición poética hebrea medieval.

Sem Tob hace uso, además, de otro artificio métrico muy caro a la

24 En el fundamental artículo de Emilio Alarcos LLORACH, "La lengua de los Proverbios morales de don Sem Tob", Revista de Filología Española, 35 (1951), pp. 249309: especialmente pp. 260-268. Es, por otra parte, frecuente en la poesía sefardí: véase Iacob M. HASSÁn, "Un género castizo sefardí: las coplas", Los sefardies: Cultura y literatura (San Sebastián: Universidad del País Vasco, 1987), pp. 103-123: pp. 110-112.

25 Otras, derivadas tanto de usos de la poesía medieval castellana como de la hebrea, las exponemos en nuestra edición citada en nota 4, pp. 40-47. 
cuaderna vía en sus primeros tiempos: la aplicación sistemática de la dialefa o, lo que es lo mismo, la no admisión de la licencia de la sinalefa para el cómputo silábico ${ }^{26}$. Recuérdese que esa exigencia métrica es propia de la cuaderna vía del siglo XIII, pero no ya de la época en que Sem Tob escribe: se trataría, por tanto, del mantenimiento de un rasgo arcaizante de la poesía culta del siglo anterior.

También en El pecado original se han querido ver restos de cuaderna vía, aunque la muy deteriorada métrica de la única versión medieval y el proceso de recreación que el poema ha padecido en la tradición oral hacen más difícil saber cuál era el cómputo silábico original, si bien parece claro que las estrofas son cuartetas monorrimas de verso largo.

En todo caso, importa la adopción de rasgos formales de la poesía judía por parte de poetas cristianos (como en el caso del $A y$, Iherusalem), y de las convenciones más acrisoladas de la poesía culta cristiana por parte de los escasos autores judíos de cuyas obras nos ha llegado muestra.

Son estas sólo algunas muestras de cómo la poesía medieval judía en lengua romance incorporó sincréticamente elementos judíos y cristianos y se difundió tanto entre cristianos como entre judíos, en una fecunda interacción.

En este artículo se expone una somera tipología de las influencias judías en la poesía castellana medieval, para después centrarse en algunos aspectos que muestran las interinfluencias entre la poesía de judíos y de cristianos: difusión y uso de poemas judíos entre lectores cristianos, posibles influjos judíos en el plano de cruzada $A y$, Iherusalem, y adopción de recursos formales de la poesía semítica en poemas cristianos y de rasgos métricos de la poesía cristiana en la judía.

This article is devoted to certain Jewish influences on Castilian medieval literature. Firstly, a brief tipology of Jewish influences on Spanish literature is exposed; afterwards, the autor focuses on some specific aspects, such as the diffusion of Jewish Castilian medieval literature among Christian readers, Jewish influences on the crusade song $A y$, Iherusalem, and finally, the use of some features of semitic poetry in Christian poems and metrical patterns of Christian poetry in Jewish poems.

26 Lo ha estudiado Isabel URía MAQUA, "Los Proverbios morales de Sem Tob y su relación con el mester de clerecía", Las tres culturas en la corona de Castilla y los sefardies. Actas de las jornadas sefardies... ([Valladolid]: Junta de Castilla y León, 1990), pp. 31-47. 